\title{
Oralidade e ensino: o trabalho com o gênero oral debate público regrado em oficinas de Língua Portuguesa
}

Gil Roberto Costa Negreiros*
Luane Guerra Vitorino**

\section{Resumo}

O presente artigo apresenta como tema os gêneros orais no ensino. Objetiva-se demonstrar o desenvolvimento oral, a partir de um trabalho sistematizado com o gênero debate público regrado, no âmbito escolar. Especificamente, descrevemos e analisamos o desenvolvimento oral de um aluno de Ensino Médio, que participou como aluno voluntário de oficinas de Língua Portuguesa que visavam trabalhar com esse gênero oral formal. Nosso embasamento teórico fundamenta-se na Linguística Textual e nas teorias de ensino e aprendizagem de gêneros. Nossa metodologia é qualitativa, ao passo que propomos uma análise interpretativa dos dados em relação ao material transcrito. Considerando que se trata de um corpus oral, utilizamo-nos de gravações e, posteriormente, de transcrições, para análise do material. Nossos resultados sinalizam que os gêneros orais, quando dinamizados em sala de aula, podem ser um importante instrumento de comunicabilidade, assim como de desenvoltura interacional e social dos alunos.

Palavras-chave: Gênero oral. Debate público regrado. Interação. Escola.

\section{Considerações iniciais}

Este artigo, parte de trabalho maior de mestrado ${ }^{1}$, apresenta como objetivo demonstrar o desenvolvimento oral, a partir de um trabalho sistematizado com o gênero debate público regrado, no âmbito escolar. Especificamente, descrevemos e analisamos o desenvolvimento oral de um aluno de Ensino Médio, a partir de intervenções didáticas com um gênero oral formal.

\footnotetext{
Doutor em Língua Portuguesa pela Pontifícia Universidade Católica de São Paulo - PUC/SP (2008), com pós-doutorado pela Universidade de São Paulo - USP. É professor adjunto III do Departamento de Letras Vernáculas da Universidade Federal de Santa Maria, atuando na graduação e na pós-graduação em Letras. É pesquisador efetivo do projeto Nurc-SP, tem experiência na área de Letras e Linguística, com ênfase nas seguintes áreas: Análise da Conversação; Sociolinguística Interacional; Linguística Textual e Pragmática. E-mail: gil.negreiros@ufsm.br

** Mestre em Estudos Linguísticos, na linha Linguagem e Interação, pela Universidade Federal de Santa Maria. É membro do grupo GOE - Gêneros orais e escritos: teoria e ensino. E-mail: luane.ufsm@gmail.com
}

\footnotetext{
Data de submissão: dez. 2018 - Data de aceite: mar. 2019 http://dx.doi.org/10.5335/rdes.v15i1.8948
} 
A oralidade é uma prática essencial, em todas as instâncias de ensino. No contexto brasileiro, os documentos oficiais, como os Parâmetros Curriculares Nacionais (PCN's), e, mais recentemente, a Base Nacional Comum Curricular (BNCC) destacam a relevância de a modalidade oral estar presente nos currículos das aulas de Língua Portuguesa, em diferentes níveis de ensino.

Nesse sentido, a sala de aula é um espaço fundamental na implantação de atividades que valorizem o trabalho com a oralidade, o que não é uma tarefa tão simples, tendo em vista as condições educacionais brasileiras, marcadas, sobretudo, pelo excesso de carga horária atribuída aos docentes, pela formação docente muitas vezes deficitária e pela falta de materiais didáticos adequados.

Pensando nesse quadro e a partir das inquietações surgidas nas discussões do Grupo de Pesquisa "GOE - Gêneros Orais e Escritos: Teoria e Ensino"2, organizamos uma série de oficinas, a partir da pesquisa-ação e das sequências didáticas, que deram condições de produzir este texto, em que demonstramos como um trabalho sistematizado com a oralidade pode ser um importante trabalho linguístico em prol da desenvoltura textual e social dos alunos.

Nosso aporte teórico fundamenta-se na interação verbal, proposta por Bakhtin/Volochinov ${ }^{3}$ (2014) e Brait (1999, 2002), no interacionismo social proposto por Vigotski (1987, 2007), bem como nas teorias do gênero oral, com Bentes
(2010), Travaglia $(2007,2017)$ e Dolz e Schneuwly (2004).

A metodologia utilizada, inicialmente, na realização de oficinas escolares, baseia-se na pesquisa-ação, a partir de Thiollent (1985)e de Tripp (2005), o que possibilita a interação entre pesquisador e sujeitos da pesquisa. Além disso, a partir de Dolz, Noverraz e Schneuwly (2004), utilizamo-nos, também nas oficinas, do método de sequências didáticas na sistematização das atividades escolares. Por fim, para análise do corpus, utilizamo-nos da metodologia qualitativa de caráter indutivo na descrição e na interpretação do material produzido nas oficinas.

Para desenvolvermos este trabalho, realizamos doze oficinas de produção textual oral, realizadas semanalmente, em uma Escola Estadual, localizada em uma região periférica do município de Santa Maria, no período de outubro a dezembro de 2017. Os sujeitos da pesquisa estavam no segundo ano do Ensino Médio e participaram dos encontros de maneira voluntária, no mesmo período das aulas de Língua Portuguesa, devido a uma parceria com a professora regente da turma.

Neste artigo, no primeiro momento, discutimos a relevância do trabalho com a oralidade na escola, bem como sobre os gêneros orais, com ênfase no debate público regrado. Na sequência, analisamos alguns fragmentos dos debates dos alunos e pontuamos algumas considerações a respeito da proposta com o gênero, 
assim como da relevância da modalidade oral ser incluída na escola enquanto um objeto autônomo.

\section{$\mathrm{O}$ ingresso da oralidade na escola}

Como aponta Marcuschi (2007), historicamente, a escrita sempre esteve relacionada a uma questão de poder. No âmbito escolar, a modalidade por muito tempo foi sinônimo de homogeneidade, estrutura, forma, e assim: "padrão".

A oralidade por muito tempo foi negligenciada, ocupando, em geral, um espaço restrito na escola, muitas vezes

Quadro 1 - Dicotomias entre fala e escrita direcionada para atividades de oralização, na tentativa de corrigir os "erros". $\mathrm{Na}$ concepção escolar, a língua padrão era a escrita e, assim, não admitia variações. À medida que essas concepções ganharam força, destacou-se a ideia de que a fala era sinônimo de espontaneidade, uma prática informal e natural que dispensava o trabalho do professor (a partir do entendimento que o aluno já sabe falar). Dessa forma, a concepção linguística mais relevante foi aquela que considerava a fala e a escrita em posições dicotômicas, como se pode observar no Quadro 1:

\begin{tabular}{|l|l|}
\hline \multicolumn{1}{|c|}{ FALA } & \multicolumn{1}{c|}{ ESCRITA } \\
\hline Contextualizada & Descontextualizada \\
Implícita & Explícita \\
Concreta & Abstrata \\
Redundante & Condensada \\
Não-planejada & Planejada \\
Imprecisa & Precisa \\
Fragmentária & Integrada \\
\hline
\end{tabular}

Fonte: Marcuschi, 2007, p. 28.

Por essa perspectiva, há uma separação radical, que restringe as práticas de linguagem e supervaloriza a escrita, o que não corresponde com o contexto diário em que, por mais que a escrita seja um instrumento linguístico muito importante, nós ainda falamos mais do que escrevemos.

Contudo, embora as duas modalidades apresentem características diferentes, não há razões para alimentarmos diferenças estanques, tendo em vista que, se considerarmos o uso da língua nas práticas sociais e em ações cotidianas, encontraremos mais relações de proximidade do que de separações:

[...] não há razão alguma para desprestigiar a oralidade e supervalorizar a escrita. Também não há razão alguma para continuar defendendo uma divisão dicotômica entre fala e escrita nem se justifica o privilégio da escrita sobre a oralidade. Ambas têm um papel importante a cumprir e não competem. Em suma, oralidade e escrita não estão em competição. Cada uma tem sua história e seu papel na sociedade (MARCUSCHI, 2007, p. 15). 
O fato é que as duas modalidades merecem ser valorizadas de acordo com as suas especificidades, considerando que ambas fazem parte do mesmo sistema linguístico. O ideal é que fala e escrita sejam incluídas no ambiente escolar e que o professor estabeleça relações a partir dos aspectos contextuais de cada uma. De acordo com Cavalcante e Melo (2006, p. 76 , grifo nosso), a oralidade "não é bem compreendida como objeto autônomo do trabalho escolar, sendo essa uma das razões que levam seu ensino a ocupar um lugar limitado na escola".

Entendemos que o "objeto autônomo" ao qual as autoras referem-se diz respeito às peculiaridades da modalidade oral, que não fazem parte do sistema linguístico escrito, como: a gestualidade, o tom de voz, a referência ao interlocutor, a entonação, a repetição de palavras. Todos esses movimentos são exclusivos da oralidade e merecem ser explorados nas aulas de língua materna.

$\mathrm{O}$ fato da oralidade ter um aspecto espontâneo não significa que a modalidade não possa ser, assim como a escrita, sistematizada. Os gêneros orais, sobretudo os mais formais, necessitam de preparação prévia. Para participar de um debate, por exemplo, é preciso estudar o tema com antecedência, elaborar questões ao grupo contrário, organizar argumentos e contra-argumentos, assim como um seminário, que exige estudo, elaboração de um roteiro, organização da fala; ou seja, o fato de o aluno dominar a fala bem antes de ingressar à escola não dispensa o trabalho do professor em relação aos gêneros orais.

\section{O conceito de gênero oral}

Travaglia (2017), na esteira de Fairclough (2004), diferencia gênero de atividade:

A atividade social é o que alguém está fazendo, para atingir determinado objetivo, enquanto gênero é um instrumento linguístico-discursivo devidamente estruturado, criado em uma esfera de atividade humana por uma comunidade discursiva, como uma forma eficiente de realizar a atividade em que o gênero tem um papel essencial (TRAVAGLIA, 2017, p. 17).

Sendo assim, a atividade é uma ação social, com finalidade específica, enquanto o gênero é um instrumento linguístico-discursivo que auxilia na realização da atividade. Considerando que os gêneros podem variar de acordo com o tempo e com o meio social em que o sujeito está inserido, as atividades serão diferentes de acordo com cada objetivo e gênero em questão.

Ainda no que se refere ao gênero oral, o autor define-o assim:

[...] é aquele que tem como suporte a voz humana (vista como a característica particular que tem o som produzido pelo aparelho fonador) e foi produzido para ser realizado oralmente, utilizando-se a voz humana independente de ter ou não uma versão escrita (TRAVAGLIA, 2017, p. 17).

Desse modo, não consideramos textos escritos que, por alguma razão, são oralizados. O gênero oral configura-se por textos que são organizados, unicamente, 
com o intuito da oralidade, como por exemplo: o debate de opinião, a exposição oral, a entrevista, a cerimônia de casamento, o batizado. Nesse sentido, apresentam características singulares e precisam ocupar um espaço na sala de aula, tendo em vista que "constituem o caminho mais produtivo para o ensino do oral, permitindo a intervenção didática do professor" (BENTES, 2010, p. 78). Cabe ao docente proporcionar o trabalho com os gêneros orais mais formais, como o debate de opinião, o debate deliberativo, a prova oral, a defesa de um trabalho científico-acadêmico, a apresentação em público, a entrevista de emprego, etc.

Evidentemente, existem outras situações sociais das quais os alunos participam enquanto interlocutores, mas é na escola, que o processo de interação pode ser desenvolvido de forma mais sistemática, pois as instâncias privadas, que são aquelas que os estudantes estão mais acostumados a interagirem, têm funcionamentos diferentes.

Desse modo, são os gêneros mais formais que contribuirão diretamente para a formação social dos sujeitos e que sozinhos, provavelmente, não terão acesso às suas especificidades. Assim, compete ao professor possibilitar atividades sistematizadas, de modo que o aluno reconheça e tenha domínio das características desses gêneros.

\section{O gênero oral debate regrado}

De acordo com Ribeiro (2009), o debate

[...] é marcado por uma linguagem persuasiva que se propõe a convencer ou persuadir o outro. Isto significa acionar mecanismos argumentativos que resultam na defesa ou elaboração de um ponto de vista, oportunizando aos interlocutores - no caso, os alunos - confrontarem suas próprias opiniões de maneira justificada, compreenderem o mecanismo das trocas discursivas e aprofundarem suas reflexões acerca de questões discutidas (RIBEIRO, 2009, p. 50).

Desse modo, o trabalho didático com o debate tem duas finalidades principais: a relevância social dos temas e argumentos, bem como o desenvolvimento das capacidades de linguagens. $O$ gênero enquanto função social tem como finalidade a construção coletiva do saber sobre um assunto dado, em especial, um tema que provoque a discordância. Objetiva a interação entre os participantes, a reflexão, o trabalho com o inesperado, o ouvir e respeitar a opinião do outro.

Já no que se refere às capacidades linguageiras, o debate pode ser explorado nos mais diversos aspectos: persuasão, operadores argumentativos, coesão, coerência. Todas essas questões contribuem para o desenvolvimento do aprendiz enquanto sujeito e refletirão na conduta dentro e fora da escola.

Segundo Liberali (2013), 
[...] assim, no movimento de questionar, contrapor, sustentar, buscar, vão sendo criadas outras possibilidades de entender, expandir e viver. Se o debate tornar pertinente e relevante o pensamento e a ação que se realizam no contexto escolar, ele terá potencial também de ser expandido para além dos muros das escolas, encontrando, nas ruas, seu local de real realização e transformação social ampla (LIBERALI, 2013, p. 109).

Como aponta a autora, o debate, a partir das características que apresenta, pode ser, também, um potencializador de transformações pessoais, considerando a função social que exerce. O aluno, quando inserido em um debate, ocupa um espaço de protagonismo em relação ao seu pensamento e as suas ações, o que contribui para a formação de um sujeito crítico e autônomo.

\section{Metodologia}

Para a realização das atividades, adotamos a metodologia da pesquisa-ação. De acordo com Tripp (2005), o método é desenvolvido por diferentes áreas. No âmbito educacional, a pesquisa-ação é "uma estratégia para o desenvolvimento de professores e pesquisadores de modo que eles possam utilizar suas pesquisas para aprimorar seu ensino e, em decorrência, o aprendizado de seus alunos" (TRIPP, 2005, p. 445).

Além disso, entendemos que a prática docente deve ser planejada e monitorada durante todo o processo de atividades com os discentes, sendo a reflexão do professor uma ação contínua.

Neste sentido, para que seja possível o desenvolvimento de um ciclo crítico e eficaz, é necessário que o professor tenha ações bem planejadas. Pensando nessa necessidade, escolhemos, para o desenvolvimento das nossas oficinas, a prática de sequências didáticas, doravante SD, de modo que o método configura-se como "um conjunto de atividades escolares organizadas, de maneira sistemática, em torno de um gênero textual oral ou escrito" (DOLZ; SCHNEUWLY, 2004, p. 82).

Os autores também afirmam que o trabalho em sala de aula deve ser organizado por meio de gêneros textuais, considerando que toda manifestação parte de algum gênero. Desse modo, apresentamos a construção que propõem para o trabalho com as SDs, conforme a figura 1.

Figura 1 - Esquema da sequência didática
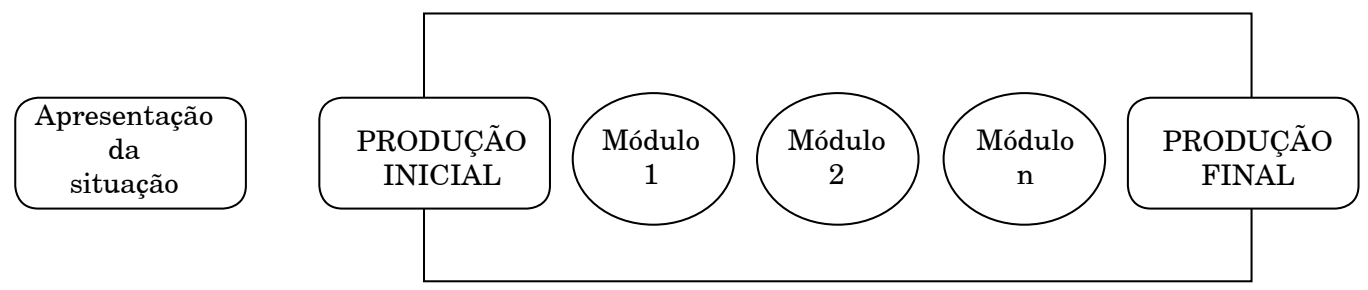

Fonte: Dolz; Noverraz e Schneuwly (2004, p. 98) 
Ainda de acordo com os autores, as SDs são um processo contínuo. À medida que a atividade finaliza, após a produção final, inicia-se outro ciclo de sequência didática. Todos esses processos ocorrem a partir de um gênero textual, seja oral ou escrito, tendo em vista que os gêneros na SD atuam como ferramentas mediadoras da aprendizagem.

\section{O corpus oral}

Como já sinalizamos anteriormente, realizamos 12 oficinas de produção textual oral, em uma escola pública, no Município de Santa Maria, no período de outubro a dezembro de 2017. Realizamos três debates, intitulados A, B e C. Após cada debate, desenvolvíamos algumas atividades para revisar alguns aspectos do gênero (as regras, a necessidade do estudo prévio, as atitudes da turma, a relevância dos temas, etc.). Tínhamos 24 alunos presentes na sala, mas somente 14 alunos entregaram os termos de autorização, em que aceitavam ser voluntários da pesquisa, então consideramos esse número de sujeitos pertencentes à pesquisa. Diante disso, para a análise do corpus, escolhemos um sujeito de pesquisa. Adotamos dois critérios para a escolha: o primeiro referiu-se à presença, pois o sujeito escolhido esteve presente em todas as oficinas e participou dos três debates (A, B, C). O segundo critério diz respeito à evolução: a aluna em questão apresenta desempenho significativo em relação à construção argumentativa dos debates, à medida que demonstra comprometimento com as atividades e apropriação em relação ao gênero.

Tendo em vista todas as particularidades que o texto oral, de fato, exige, e considerando que o corpus se refere ao ambiente da sala de aula, com oficinas semanais, utilizamo-nos de gravações e, posteriormente, de transcrições, a fim de garantir o registro das atividades, considerando que "ensinar o oral implica desenvolver o hábito de registrar, para ter o traço das produções dos alunos. [...] $\mathrm{O}$ registro permite escutar-se, reescutar os outros, observar, analisar, criticar-se, fazer propostas para a melhora dos outros" (DOLZ, SCHNEUWLY; PIETRO, 2004, p. 243).

Em relação aos critérios de análise, baseamo-nos em Travaglia (2007) que, amparado em Bakhtin/Volochinov e em Fairclough (2004), apresenta cinco critérios para a caracterização de gêneros. De acordo com o teórico, "essa caracterização é fundamental para a identificação e distinção das categorias a que os textos podem pertencer" (TRAVAGLIA, 2007, p. 39).

O autor define então parâmetros que podem categorizar o gênero:
a) o conteúdo temático;
b) a estrutura composicional;
c) os objetivos e funções sociocomu- nicativas;
d) as características da superfície linguística;
e) as condições de produção. 
Para fins desta discussão, escolhemos três elementos: a composição, os objetivos/função sociocomunicativa e as características da superfície linguística, com ênfase no que se refere aos operadores argumentativos. Escolhemos esse elemento por considerá-lo um recurso fundamental no processo argumentativo.

A estrutura composicional relaciona-se à importância de subitens que fazem parte dos gêneros, o que o autor define como superestrutura. A superestrutura composicional refere-se aos desdobramentos do gênero, em que são analisados os aspectos formais. $\mathrm{O}$ critério intitulado objetivos e funções sociocomunicativas refere-se à intenção que o locutor/enunciador tem ao produzir determinado gênero. Por exemplo, o alvará tem o objetivo de conseguir uma permissão; um convite, de solicitar uma presença, e um contrato de firmar concordância em relação a algo. Por fim, o critério das características da superfície linguística "podem referir-se a qualquer plano da língua (fonológico, morfológico, sintático, semântico, pragmático) ou nível (lexical, frasal, textual)" (TRAVAGLIA, 2007, p. 62). Trata-se, então, de todos os recursos e propriedades da língua.

Apresentaremos, a seguir, os excertos com as falas do sujeito de pesquisa e, na sequência, tecemos comentários analíticos em relação a cada trecho de debate. Retomaremos, também, os conceitos dos três critérios que escolhemos para realizar a análise, a partir das considerações de Travaglia (2007): a composição, os objetivos/função sociocomunicativa e as características da superfície linguística, com ênfase nos conceitos de operadores argumentativos, a partir de Koch (1984; 2006) e Almeida (2001). Separamos os debates por trechos, por considerar que facilitaria a dinâmica de análise, bem como a compreensão do leitor. Como já mencionamos anteriormente, são três debates, intitulados A, B e C. Tendo em vista que se refere a um debate regrado, em alguns momentos, mencionaremos outros sujeitos debatedores, considerando que a manifestação do nosso sujeito de pesquisa está relacionada às outras falas.

\section{Trecho 1 (Debate A)}

01 S6 tipo::: entrar na fila de deficiente ou de grávida...ontem eu pensei em fazer isso ((risos))

S3 como assim?

S6 Eu tava na fila com uma roupa larga aí eu pensei que eu podia passa mas eu achei muito errado...eu:: eu fiquei com vergonha assim como estaciona em local de deficiente ou em local proibido não tá certo... na verdade eu acho o:: o povo é corrupto.. o povo vai lá e (trama) primeiro... uma pessoa morre e daí outra fica recebendo por ela e isso é errado. 
Esse foi o primeiro contato que tivemos com os alunos, em relação ao desenvolvimento das oficinas. Num contato anterior, havíamos conversado com eles sobre os objetivos da pesquisa e sobre os termos de autorização.

Levamos, então, um texto a respeito da corrupção e, após a leitura, provocamos os discentes para que se manifestassem em relação ao tema e à tese defendida pelo autor.

Após a leitura, a mediadora do debate apresentou oralmente a seguinte questão: "Segundo o autor as pequenas corrupções como furar fila, estacionar em local proibido, receber troco para mais e não devolver, não são tão graves quanto a corrupção dos políticos. O que vocês acham? Concordam?"

A discussão foi sucinta, tendo em vista que os estudantes não tinham muitos argumentos. Em relação ao S6, o sujeito pouco apresenta os aspectos da composição, tendo em vista que, apesar de manter uma atitude contida e respeitosa com os demais colegas e de não interromper as falas, não demonstra total clareza em sua arguição, como é possível perceber no questionamento "como assim", do S3. Além disso, S6 não responde ao tema com argumentos consistentes, sua exposição ocorre com exemplos do cotidiano.

Assim, desenvolvemos, por meio das sequências didáticas, uma série de atividades com a intenção de aproximar os estudantes ao gênero. E, após essas oficinas, realizamos o segundo debate, intitulado debate B. O tema foi escolhido pelos alunos, (pena de morte). Diferentemente do debate anterior, houve estudo prévio do tema e divisão da turma, de acordo com a posição escolhida pelos estudantes (favoráveis e contrários).

A pesquisadora, que interveio como mediadora, leu um pequeno texto acerca do assunto e introduziu a discussão com a questão: "Tendo em vista que o direito à vida é um direito constitucional, a pena de morte, nesse caso, não estaria violando um dos principais direitos previstos na Declaração Universal dos Direitos Humanos?"

Um sujeito, contrário à pena de morte, responde e defende que os criminosos sejam apenas presos e trabalhem para "compensar" seus delitos:

S2 Eu acho que a vida é um direito e:: e o preso tem que trabalhar... entendeu? o preso vai trabalhar na cadeia e essa família do preso teve um...um rombo tanto na sua família como no dinheiro né...como são homens a família depende mais do homem...então...nesse meio... ele trabalharia não tem como recompensa...mas mas no caso o preso trabalharia e geraria uma riqueza e boa parte dessa riqueza poderia ir pra família...não como...como...tentando recompensar porque não tem como... a pessoa se foi e não tem como ela voltar....então substituindo...ela poderia trabalhar e boa parte dessa riqueza ir pros carcereiros... dessas pessoas que vão ter que cuidar deles...no caso eles vão ter que plantar e muitas pessoas vão ter que cuidar deles eles poderiam pagar...essa parte da riqueza iria pra eles..." 
O sujeito S6 inicia, então, sua fala contrariando o colega:

\section{Trecho 1 (Debate B)}

Então... eu acho que NÃO justificaria tu tirar a vida de uma pessoa e:: e:: depois de um tempo tu ficar preso ou trabalhar pra pagar um dinheiro e suprir um pouco a falta de uma família - - se eu entendi direito é isso que tu quis dizer - - no caso se fosse uma mãe que os filhos fossem criAdos sem uma mulher porque a maioria das vítimas são vítimas de estupro... no Brasil cinco mulheres por hora são vítimas de estupro ou seja 120 mulheres por dia e na maioria das vezes por AZAR eles sobrevivem::: e.... entÃO tu pensa numa pessoa que estuprou uma mulher e sabe que vai ficar seis meses na prisão se for o caso ou vai pagar uma quantia em dinheiro e ta na rua de novo...a gente sabe:: que ele não vai parar... não foi a primeira e não será a última...já é experiente no assunto...a gente vai deixa que uma alma boa toque o coração dele e se arrependa? Que ele trabalhe por um tempo e pague uma quantia em dinheiro ou a gente vai preferir dar um basta nisso e evitar que mais pessoas sejam vítimas das mesmas mãos?

Nesse primeiro trecho, já percebemos uma postura mais coerente com o gênero, ao passo que $\mathrm{S} 6$ demonstra interesse em desconstruir a fala do colega, apresentando argumentos que possam sustentar o seu ponto de vista. O sujeito inicia sua exposição de forma polida, quando menciona, na primeira linha, "eu acho que..." e com o uso do termo "justificaria", referindo-se a uma possível retratação acerca de um episódio polêmico. Em seguida, a argumentação toma um tom mais consistente, de modo que S6 contraria a ideia do colega e retoma o argumento dele quando menciona "se eu entendi direito é isso que tu quis dizer".

$\mathrm{Na}$ sequência, S6, apesar de não citar a fonte, apresenta um argumento de provas concretas - tipo de argumento que foi trabalhado no período de oficinas, que se refere a "fatos, dados estatísticos, exemplos e ilustrações para comprovar a veracidade do que se diz" $(\mathrm{KOCH}$; ELIAS, 2016, p. 25). Além dos argumentos, as perguntas retóricas reafirmam a sua posição. 


\section{Trecho 2 (Debate B)}

Mas e se o cara for só preso? Ele tem que se preso

S6 Mas a primeira oportunidade que o preso tem de sair pra rua....ele vai lá e comete o mesmo crime

$\mathrm{E}$ tu acha mesmo que a pena de morte ia mudar alguma coisa?

S6 mudaria...você ia impedir que milhares sofressem a mesma coisa injustamente... que inocentes passassem pelo que uma pessoa passou... tu tá impedindo que outras pessoas passem pela mesma coisa:: é...é claro que mudaria

No trecho citado, S6 mantém seu posicionamento, de forma coerente, respondendo às questões de S10. Apesar de ser incisivo, o sujeito não desrespeita $o$ colega, não se sobrepõe à voz do outro e apresenta clareza no desenvolvimento das suas ideias. O uso do operador "mas", logo no início da argumentação, apresenta oposição em relação à fala do outro sujeito e tem como intenção desconsiderar a pergunta do colega, na medida em que o termo é seguido de um contra-ar- gumento: "Mas a primeira oportunidade que o preso tem de sair pra rua.... ele vai lá e comete o mesmo crime".

Percebemos que há uma sequência lógica nos argumentos de S6, considerando que o sujeito mantém a mesma posição, repete e retoma algumas expressões e utiliza-se dos operadores argumentativos e das perguntas retóricas para desconstruir as falas dos integrantes do grupo contrário.

\section{Trecho 3 (Debate B)}

S2 só que a gente não sabe se essa pessoa vai cometer crime de novo...tu não sabe...tu não sabe o futuro dela...não dá pra dizê que sim

S6 mas a justiça é falha...se ele souber que a justiça é falha ele vai ficar um pouquinho preso SE for preso e vai sair...tu acha mesmo que ele vai parar de matar? ele vai parar de fazer o que ele faz por isso? É claro que não...

S2 e como garantir que ele não vai ser punido?

como te falei...ele vai ficar impune...se ele for preso vai ser por pouco

S6 tempo...você acha mesmo que ele vai parar? "cê" acha que alguma alma bondosa vai tocar o coração dele e ele vai parar? tu acha que foi a primeira vez?... se a pessoa não tiver disposta a melhorar ela não vai melhorar... não vai sair da cadeia alguém produtivo pra sociedade. 
O sujeito inicia sua exposição mantendo os argumentos utilizados nos trechos anteriores, em relação à perpetuação de um crime. No primeiro momento, contraria o colega, em: "mas a justiça é falha... se ele souber que a justiça é falha ele vai ficar um pouquinho preso $\mathrm{SE}$ for preso $\mathbf{e}$ vai sair...", condiciona as situações, como em "como te falei...ele vai ficar impune... se ele for preso vai ser por pouco tempo... você acha mesmo que ele vai parar? e, mais uma vez, apresenta perguntas retóricas para reforçar a sua tese, em "cê acha que alguma alma bondosa vai tocar o coração dele e ele vai parar? tu acha que foi a primeira vez?...”.

Percebemos que as questões não têm como objetivo uma resposta do interlocutor, mas, sim, manter o turno de $\mathrm{S} 6 \mathrm{e}$ reafirmar as ideias defendidas anterior- mente. De acordo com Fávero, Andrade e Aquino (2006) as perguntas retóricas, na fala

[...] ocorrem quando o falante elabora uma Pergunta com o intuito de que o ouvinte não responda, porque aquele já conhece a Resposta e é só uma questão de procurá-la na memória. Verifica-se que esse tipo de Pergunta é usado como recurso, entre outros, para manter o turno ou para estabelecer contato (FÁVERO, ANDRADE E AQUINO, 2006, p. 161).

No segundo momento, ao ser questionada, a aluna retoma as ideias já apresentadas quando afirma: "como te falei...". Com o uso do operador "como", S6 intensifica seus argumentos. Com diferentes argumentos, o sujeito constrói, ao longo dos excertos, a mesma linha de raciocínio defendida desde o começo do debate e mantém sua posição: a defesa da pena de morte.

\section{Trecho 4 (Debate B)}

S8 E nos países onde a pena de morte existe...vocês sabem se:: se a criminalidade diminui mesmo?

\section{S6 em alguns lugares dos Estados Unidos sim... e da China também...}

No pequeno trecho, evidenciamos a tentativa de desconstrução do S8, quando questiona a eficácia do ato defendido por S6 (a pena de morte), ao passo que nosso sujeito de análise sustenta sua posição, na medida em que domina a questão e apresenta um resultado positivo, mesmo que não tenha apresentado detalhes, como, por exemplo, as cidades de cada país ou os índices de diminuição da criminalidade, o que corroboraria a sua tese.
Mesmo que não apresente a informação precisa, o sujeito responde a questão e sustenta sua tese defendida desde o começo do debate, demonstrando coerência em relação à atividade proposta, tendo em vista que o debate tem por objetivo "construir, de um ponto de vista racional, uma explicação, recorrendo a experiências individuais e sociais num quadro espacial e temporal de uma situação com finalidade persuasiva" (KOCH; ELIAS, 2016, p. 24). 
Percebemos que os debates, à medida que tomam proporção, têm a polêmica como elemento principal. O envolvimento dos sujeitos com a atividade também justifica-se pelo conteúdo opositivo que provoca: são dois grupos, com teorias divergentes sobre um assunto polêmico e, a cada argumento apresentado, um contra-argumento com viés polêmico também é inserido. Assim, compreendemos que mais do que chegar a uma conclusão coletiva ou alterar o ponto de vista do outro sobre o assunto, o gênero debate tem como objetivo a construção opinativa individual sobre o tema, considerando que cada aluno já traz para o debate a sua posição e não há uma renúncia dos grupos, mas sim a confrontação, na tentativa de defender a tese já definida.

Após o primeiro debate formal, que intitulamos debate $\mathrm{B}$, realizamos ainda algumas oficinas para revisar alguns pontos que julgamos necessários, como a importância do estudo prévio (para aqueles alunos que não tinham se preparado), bem como a relevância de apresentar as fontes, quando trazem exemplos ou citações. Depois de algumas discussões em relação ao tema, os aprendizes chegaram a uma decisão e optaram pelo tema "aborto".

No momento do debate, a pesquisadora, novamente como mediadora, leu um pequeno texto e introduziu a questão inicial: "A legalização do aborto não seria um consentimento de um crime contra a vida?"

Um sujeito, contrário ao aborto, concordou com a questão apresentada pela mediadora e alegou que o procedimento é ilegal e criminoso:

S2 Sim... porquea:: a questão do aborto ele é assassinato querendo ou não é uma vida... pode dizer mas não nasceu mas é uma vida.

O sujeito S6 inicia, então, contrariando a declaração do colega:

\section{Trecho 1 (Debate C)}

S6 isso é muito relativo porque a mulher que é rica vai poder fazer o procedimento...ela vai achar um lugar...a mulher rica não vai sofrer... ahhTAAnto... vai ser vamos dizer legal...vai ser num lugar limpo adequado e a mulher pobre não... vai ser clandestinamente num lugar sujo não adequado e:: e...de maneiras que ela mesma pode fazer e:: em 45 por cento dos abortos as mulheres morrem

S2 É que isso é uma irresponsabilidade... a questão é que:: na maioria dos abortos que se tem registro a maioria são de pessoas... de adolescentes que fizeram né o::: o sexo sem né sem a proteção e aconteceu aquilo...a maioria são jovens e adolescentes

S6 não... na verdade:: a maioria são mulheres entre quatorze e trinta e nove anos....de baixa escolaridade....negras e pardas que moram em periferias... 
No primeiro trecho, já percebemos um posicionamento enfático e seguro, na medida em que o sujeito relativiza a opinião do colega e traz dados e exemplos que desconstroem os argumentos de S2, demonstrando, assim, estudo prévio a respeito do tema.

Em um primeiro momento, S6, além de relativizar a fala do outro debatedor, apresenta comparações em relação aos fatos, quando menciona sobre a mulher rica versus a mulher pobre e finaliza com a comprovação, que em " 45 por cento dos abortos as mulheres morrem". Mesmo sem apresentar a fonte, consideramos um argumento de provas concretas, pois indica estudo prévio da aluna.

Entendemos que S6 apropria-se de conceitos apresentados no período das oficinas, no que se refere às estratégias para iniciar uma argumentação, como: definir um ponto de vista e apresentar fatos (KOCH; ELIAS, 2016).

\section{Trecho 2 (Debate C)}

S2 mas a grande maioria que procura também é pessoas que tem... como que vou dizê...que tem condições de fazer isso

S6 que condições? a maioria das pess/ das mulheres que procuram aborto clandestino... são mulheres de baixa renda que:: moram em periferias e que tem baixa escolaridade

Novamente, o sujeito apresenta uma questão para desconstruir o argumento do colega e reforça, nas duas últimas linhas, a comprovação que já tinha apresentado antes, em: "são mulheres de baixa renda que:: moram em periferias e que tem baixa escolaridade", recorrendo a uma argumento de autoridade, com a intenção de comprovar sua tese.

\section{Trecho 3 (Debate C)}

S7 ta:: tipo assim uma pessoa que ela assim não poderia ter procurado outros meios? apesar da nossa saúde ser tão precária assim a gente tem meios de evitar uma gravidez

S6 todos são 100 por cento seguros?

S7 são seguros

S6 100 por cento seguros?

S7 não 100 por cento mas tipo todo...a....se a camisinha estourar tem o anticoncepcional tem a pílula do dia seguinte... tem um monte de coisa

S6 prejudicial à saúde... a gente tá falando da saúde da mulher ainda 
No terceiro trecho, evidenciamos que, a partir de questões bem enfáticas, S6 tenta desconstruir os argumentos de S7. O objetivo do sujeito é comprovar a sua posição por meio de perguntas que, ao final, deixam o outro debatedor sem argumentos.

Nesse trecho, a troca de ideias entre os dois sujeitos também tem um aspecto polêmico, no jogo de pergunta-resposta dos grupos, o que demonstra um conflito de ideias, entendendo que "o denominador comum de todos os enunciados polêmicos, em todos os gêneros, não é a violência verbal, mas sim o conflitual" (AMOSSY, 2017, p. 53). De acordo com a autora, o debate não tem como objetivo um ataque pessoal entre os debatedores, assim como não objetiva, prioritariamen- te, chegar a uma conclusão coletiva. O principal elemento é a dicotomização das posições defendidas por cada debatedor, de modo que essa interação entre os participantes torna-se um movimento de gestão de um conflito, em que o mais importante é o modo como cada participante gerencia o aspecto conflitual.

Em relação aos critérios linguísticos, o termo "ainda", utilizado na última fala do sujeito, em "prejudicial à saúde... a gente tá falando da saúde da mulher ainda", é um recurso para retomar os argumentos apresentados anteriormente, de modo que se caracteriza como um elemento "introdutor de mais um argumento e marcador temporal" (ALMEIDA, 2001, p. 45).

\section{Trecho 4 (Debate C)}

S2 e nos países em que o aborto é legalizado...vocês sabem se se não é um problema?

S6 não... a taxa é muito menor e nos paises...o:: o lugar que mais tem abortos ilegais ocorrem na A...na Ásia e na América Latina... 97 por cento dos abortos do MUNdo ocorrem lá

Nesse trecho, o outro debatedor tenta reforçar seu ponto de vista apresentando um questionamento muito recorrente na discussão de temas polêmicos: a prova de que tal fato é realmente eficiente, considerando que a polêmica, no processo de interação, "se diferencia das interações argumentativas ordinárias porque ela tende sistematicamente para uma dicotomização que dificulta a busca de acordo entre as partes adversárias" (AMOSSY, 2017, p. 55).
Os estudantes não estão dispostos a um acordo sobre o tema, para realizarem uma conclusão final sobre a atividade. Cada grupo defende, veementemente, a sua posição e demonstra apenas o interesse em manter as suas ideias. Em um primeiro momento, $\mathrm{S} 6$ responde a pergunta e afirma que há registro positivo nos locais onde o aborto é legalizado, embora não mencione os países. $\mathrm{Na}$ sequência, cita algo que não foi questionado. $\mathrm{O}$ colega referia-se à legalização 
do fato e $\mathrm{S} 6$ responde sobre os processos ilegais. Contudo, não consideramos a menção como fuga do tema ou dispersão, mas como intenção de apresentar mais um dado, na tentativa de corroborar a sua tese.

\section{Trecho 5 (Debate C)}

S10 eu ACHO que uma vida é sempre uma vida e no caso de:: de estupro ela deveria ter e dar pra adoção porque a criança não tem culpa né?

S6 e o psicológico dessa mulher? é contra a vontade dela...vai tá gerando um filho que foi de um crime

S10 tinha que ser assim oh...não em casos de estupro né mas em casos normais ela escolhe... quer ou não quer o filho e a partir dos 16 anos pra cima ela não pode escolher isso porque ela tem responsabilidade.. ela já tem um:: a a inteligência um pouco maior no caso se ela engravidar ela sabe que fez isso e isso a e partir dos 15 ano pra baixo:: é...é considerado uma criança... é uma criança .

S6 no Brasil no Brasil dos sete aos onze anos se ela engravidar e quiser abortar é:: é possível

S10 sete anos vai engravidar?

S6 gente isso acontece...

Nesse último trecho, S6, no primeiro momento, contra-argumenta o colega com uma pergunta e já apresenta a resposta, sinalizando desacordo com a proposta de S10, de maneira muito significativa, quando afirma sobre $o$ "psicológico da mulher em casos de violência". Na sequência, o debatedor apresenta uma ideia sem muita coerência, por meio de suposições, e o sujeito em questão novamente responde, com informações precisas a respeito da lei no Brasil em relação ao tema, o que prova, mais uma vez, sua preparação prévia para o debate.

No que se refere ao nosso sujeito de análise, consideramos que S6 melhora seu desempenho comunicativo a partir do debate $\mathrm{B}$, à medida que sinaliza conhecimento sobre o tema, pesquisa prévia, respeito às demais falas, além de trazer argumentos de autoridade, apresentando, assim, a mesma postura no debate $\mathrm{C}$.

Em relação aos critérios de análise que utilizamos, no que tange à estrutura composicional, S6, de maneira geral os segue. A aluna apresenta uma postura adequada, respeita os tempos de fala, assim como o posicionamento dos colegas e segue as regras pré-estabelecidas, sem nenhuma intercorrência.

Em relação aos objetivos/função sociocomunicativa, compreendemos que o su- 
jeito segue os parâmetros, à medida que apresenta argumentos coerentes com as propostas, demonstra verdadeiro interesse em dialogar com os colegas e tenta convencê-los de seus posicionamentos, o que sinaliza uma possível apropriação de S6 em relação ao gênero oral.

Por fim, sobre as características da superfície linguística, em geral, o sujeito apresenta uma linguagem cuidada e adequada à formalidade que o gênero exige. Em relação aos operadores argumentativos, são utilizados de forma satisfatória e coerente com as manifestações. $\mathrm{O}$ uso dos operadores é uma estratégia argumentativa do sujeito para expressar suas opiniões e tentar convencer os demais colegas, principalmente com o acréscimo de ideias e com elementos de contradição, na intenção de desfazer o argumento do grupo oposto.

Sem dúvida, precisaríamos de mais tempo para realizar mais atividades e reavaliá-las frequentemente, o que tornaria o processo com o gênero um ciclo contínuo e eficiente, mas, pelo que foi possível desenvolver, sinalizamos um crescimento da competência oral de S6.

\section{Considerações finais}

No ensino de Língua Portuguesa, a oralidade deve ocupar o mesmo espaço da produção escrita, da leitura e dos aspectos gramaticais. A oralidade, quando trabalhada de forma consciente e metodológica (como a partir da ideia de gênero), produz resultados relevantes, dando ao processo de ensino maior dinamicidade. Tais axiomas são reforçados pelos resultados alcançados em nossa pesquisa, já que apresentamos as descrições e as análises de um processo eficaz com o gênero oral debate regrado.

Diferentemente do que muito se acreditava (ou ainda acredita) sobre o ensino da oralidade, é possível desenvolver um trabalho sistematizado a partir de gêneros orais, enfatizando diferentes elementos dos aspectos orais, de uma forma equilibrada com a modalidade escrita. Assim, mais do que somente reconhecer que os gêneros orais precisam ser trabalhados na escola, é necessária ampla discussão sobre o tema para que o gênero seja um instrumento valorizado no ensino de língua, considerando que ele pode ser um mediador no desenvolvimento das habilidades de leitura, escrita, produção oral, além de outras questões sociais diversas. Desse modo, entendemos que a escola não deve apenas oportunizar aos alunos a análise de determinadas práticas orais, como também "deve fornecer os contextos, as motivações e as finalidades para o exercício de diferentes oralidades, na sala de aula e fora dela" (BENTES, 2010, p. 139).

Com este artigo, esperamos ampliar as reflexões acerca da modalidade oral em diferentes níveis de ensino, de modo que os professores possam sentir-se motivados a trabalharem com os gêneros orais, e que, assim, possam enfatizar aos discentes os benefícios linguísticos e sociais que o ingresso da modalidade oral na sala de aula pode oferecer. 


\section{Orality and teaching: the work with the oral gender public debate ruled in portuguese language offices}

\section{Abstract}

The present paper presents as subject the oral genres in the teaching. The aim is to demonstrate oral development, based on a systematized work with the genre public regimented debate, in the school context. Specifically, we describe and analyze the oral development of a high school student, who participated as a volunteer student of Portuguese language workshops which aimed to work with this oral genre. Our theoretical basis is based on Textual Linguistics and on theories of teaching and learning of genres. Our methodology is qualitative, while we propose an interpretative analysis of the data in relation to the transcribed material. Considering that it is an oral corpus, we use recordings and, later, transcripts, to analyze the material. Our results indicate that oral genres, when dynamized in the classroom, can be an important instrument of communicability, as well as the students' interactional and social development.

Keywords: Oral gender. Public regimented debate. Interaction. School.

\section{Notas}

1 VITORINO, Luane Guerra. Oralidade na escola: um trabalho com o gênero oral debate regrado em oficinas de língua portuguesa. 2018. 156 p. Dissertação (Mestrado em Letras). Universidade Federal de Santa Maria, Santa Maria, RS, 2018.
2 O Grupo de Pesquisa "GOE - Gêneros Orais e Escritos: teoria e ensino" está vinculado ao Programa de Pós-Graduação em Letras da Universidade Federal de Santa Maria. Acesso em : dgp.cnpq.br/dgp/espelhogrupo/5570011901272075

3 Não discutiremos questões de autoria. Neste texto, nosso referencial será mencionado como Bakthin/Volochinov (2014).

\section{Referências}

ALMEIDA, Lucimar. Análise semântica de operadores argumentativos em textos publicitários. 2001, 154 p. Dissertação (Mestrado em Letras) - Instituto de Letras e Linguística, Universidade Federal de Uberlândia, Uberlândia, 2001.

AMOSSY, Ruth. Apologia da polêmica. São Paulo: Contexto, 2017.

BAKHTIN, Mikhail; (VOLOCHINOV, Valentin). Marxismo e filosofia da linguagem. 16. ed. São Paulo: Hucitec, 2014.

BENTES, Anna. Linguagem oral no espaço escolar: rediscutindo o lugar das práticas e dos gêneros orais na escola. (Coleção explorando o ensino). Brasília: Ministério da Educação, Secretaria de Educação Básica, 2010.

BRAIT, Beth. O processo interacional. In: PRETI, Dino. Análise de textos orais. (Org.). 4. ed. São Paulo: Humanitas Publicações FFLCH/USP, 1999, p. 189-214. (Projetos Paralelos: v.1).

. Língua e Linguagem. São Paulo: Ática, 2002.

CAVALCANTE, Marianne; MELO, Cristina. Oralidade no ensino médio: em busca de uma prática. In: BUNZEN, Clecio. MENDONÇA, Márcia. (Org.). Português no ensino médio e formação do professor. São Paulo: Parábola Editorial, 2006, p. 181-198.

DOLZ, Joaquim; SCHNEUWLY, Bernard. Gêneros e progressão e expressão oral e escrita - elementos para as reflexões sobre uma experiência suíça (francófona). In: DOLZ, 
Joaquim; SCHNEUWLY, Bernard. (Org.). Gêneros orais e escritos na escola. Campinas, SP: Mercado de Letras, 2004, p. 41-70.

DOLZ, Joaquim; SCHNEUWLY, Bernard; PIETRO, Jean-François de. Relato de uma sequência didática: o debate público. In: DOLZ, Joaquim; SCHNEUWLY, Bernard. (Org.). Gêneros orais e escritos na escola. Campinas, SP: Mercado de Letras, 2004. p. 247- 277.

DOLZ, Joaquim; NOVERRAZ, Michèle, SCHNEUWLY, Bernard. Sequências didáticas para o oral e a escrita: apresentação de um procedimento. In: DOLZ, Joaquim; SCHNEUWLY, Bernard. (Org.). Gêneros orais e escritos na escola. Campinas, SP: Mercado de Letras, 2004. p. 95-128.

FAIRCLOUGH, Norman. Analysing Discourse: Textual analysis for social research. New York: Taylor e Francis e-library, 2004.

FÁVERO, Leonor Lopes; ANDRADE, Maria Lúcia; AQUINO, Zilda. O par dialógico pergunta - resposta. In: JUBRAN, Clélia; KOCH, Ingedore (Org.). Gramática do português culto falado no Brasil. Campinas: Editora da Unicamp, 2006. p. 133-166.

$\mathrm{KOCH}$, Ingedore. Argumentação e Linguagem. São Paulo: Cortez, 1984.

. Desvendando os segredos do texto. 5 . ed. São Paulo: Cortez, 2006.

; ELIAS, Vanda Maria. Ler e compreender: os sentidos do texto. São Paulo: Contexto, 2016.

LIBERALI, Fernanda Coelho. Argumentação em contexto escolar. Campinas, SP: Pontes Editores, 2013.

MARCUSCHI, Luiz Antônio. Da fala para a escrita: atividades de retextualização. 8. ed. São Paulo: Cortez, 2007.

RIBEIRO, Roziane Marinho. Aconstrução da argumentação oral no contexto de ensino. São Paulo: Cortez, 2009.
THIOLLENT, Michel. Metodologia da Pesquisa-Ação. São Paulo: Cortez, 1985.

TRAVAGLIA, Luiz Carlos. A caracterização de categorias de texto: tipos, gêneros e espécies. ALFA, São Paulo, v. 51 n. 1, p. 39-79, 2007. Disponível em: http://www.alfa.ibilce. unesp.br/download/v51- 1/03-Travaglia.pdf. Acesso em 10 de abril de 2018.

. Gêneros orais e caracterização. Olhares e Trilhas. v. 19, n. 2, p. 13-24, jul. - dez. 2017.

TRIPP, David. Pesquisa-ação: uma introdução metodológica. Tradução Lólio Lourenço de Oliveira. Revista de Educação e Pesquisa. São Paulo, v. 31, n. 3, p. 443-466, set./dez. 2005.

VIGOTSKI, Lev Semenovitch. Pensamento e Linguagem. São Paulo: Martins Fontes Editora, 1987.

A formação social da mente: o desenvolvimento dos processos psicológicos superiores. 7. ed. São Paulo: Martins Fontes, 2007. 